\title{
Plasma Supported Deposition of Amorphous Hydrogenated Carbon (a-C:H) on Polyamide 6: Determining Interlayer Completion and Dehydrogenation Effects during Layer Growth
}

\author{
Torben Schlebrowski ${ }^{1, *} \mathbb{\infty}$, Henriette Lüber ${ }^{1}$, Lucas Beucher $^{1}$, Melanie Fritz ${ }^{1} \mathbb{D}$, Youssef Benjillali ${ }^{2}$, \\ Mohammed Bentaouit ${ }^{2}$, Barbara Hahn ${ }^{2}$, Stefan Wehner ${ }^{1}\left[\right.$ and Christian B. Fischer ${ }^{1,3, *(D)}$ \\ 1 Department of Physics, University Koblenz-Landau, 56070 Koblenz, Germany; \\ hlueber@uni-koblenz.de (H.L.); lucasbeucher@uni-koblenz.de (L.B.); melfritz@uni-koblenz.de (M.F.); \\ wehner@uni-koblenz.de (S.W.) \\ 2 Department of Material Analysis, RheinAhrCampus, University of Applied Sciences, \\ 53424 Remagen, Germany; youssef-ben@live.de (Y.B.); mbentaou@rheinahrcampus.de (M.B.); \\ barbara-m-hahn@t-online.de (B.H.) \\ 3 Materials Science, Energy and Nano-Engineering Department, \\ Mohammed VI Polytechnic University, Ben Guerir 43150, Morocco \\ * Correspondence: schlebrowski@uni-koblenz.de (T.S.); chrbfischer@uni-koblenz.de (C.B.F.)
}

Citation: Schlebrowski, T.; Lüber, H.; Beucher, L.; Fritz, M.; Benjillali, Y.; Bentaouit, M.; Hahn, B.; Wehner, S.; Fischer, C.B. Plasma Supported Deposition of Amorphous

Hydrogenated Carbon (a-C:H) on Polyamide 6: Determining Interlayer Completion and Dehydrogenation Effects during Layer Growth Polymers 2021, 13, 1886. https:// doi.org/10.3390/polym13111886

Academic Editor: Sasaki Takashi

Received: 27 April 2021

Accepted: 3 June 2021

Published: 6 June 2021

Publisher's Note: MDPI stays neutral with regard to jurisdictional claims in published maps and institutional affiliations.

Copyright: (c) 2021 by the authors. Licensee MDPI, Basel, Switzerland. This article is an open access article distributed under the terms and conditions of the Creative Commons Attribution (CC BY) license (https:// creativecommons.org/licenses/by/ $4.0 /)$.

\begin{abstract}
Polyamide 6 (PA6) is a commonly used material in many different sectors of modern industry. Herein, PA6 samples were coated with amorphous carbon layers (a-C:H) with increasing thickness up to $2 \mu \mathrm{m}$ using radio frequency plasma enhanced chemical vapor deposition for surface adjustment. The morphology of the carbon coatings was inspected by ex situ atomic force microscopy and scanning electron microscopy. Surface wettability was checked by contact angle measurements. The chemical composition was analyzed using the surface sensitive synchrotron X-ray-based techniques near-edge $\mathrm{X}$-ray absorption fine structure and X-ray photoelectron spectroscopy, supported by diffuse reflectance infrared Fourier transform spectroscopy. Particular attention was paid to the coating interval from 0 to $100 \mathrm{~nm}$, to specify the interlayer thickness between the PA6 polymer and a-C:H coating, and the region between 1000 and $2000 \mathrm{~nm}$, where dehydrogenation of the a-C:H layer occurs. The interlayer is decisive for the linkage of the deposited carbon layer on the polymer: the more pronounced it is, the better the adhesion. The thickness of the interlayer could be narrowed down to $40 \mathrm{~nm}$ in all used methods, and the dehydrogenation process takes place at a layer thickness of $1500 \mathrm{~nm}$
\end{abstract}

Keywords: PECVD plasma coating; gradual film deposition; synchrotron radiation; wettability; a-C:H polymer interlayer

\section{Introduction}

Polyamide polymers are widely used in many aspects of modern life such as mechanical, electrical, and sanitary engineering [1], in the automotive [2] and construction industries, and in medical technology, e.g., for artificial joints [3], surgical instruments, and as suture material [1]. Additionally, polyamide 6 (PA6) is used for food and medical packaging [4] and for composite materials [5,6]. Nevertheless, probably the best known application of polyamides is their use as nylon for clothes and ropes [7]. Polymers (including polyamides) have in common great advantages (elasticity, formability, low weight, and good usability in a wide range of temperatures as well as chemical resistance) [8,9], but their applicability is limited due to, e.g., low hardness, low abrasion resistance, or poor mechanical properties [8].

One possible way to adapt polymers for further applications is to perform comprehensive surface modification by the deposition of hydrogenated amorphous carbon [10-16]. Although polyamides are widely used in their application, only little research has been 
done on surface modification with such coatings [17]. The films deposited mainly consist of carbon and contain $\mathrm{sp}^{2}$ ( $\pi$ and $\sigma$ ) and $\mathrm{sp}^{3}$ bonding sites with hydrogen incorporated in the network $[11,18,19]$. Depending on the dominant bond, such layers can have diamond-like properties (high hardness, chemical inertness, high electrical resistance) for a low $\mathrm{sp}^{2} / \mathrm{sp}^{3}$ ratio or more graphite-like characteristics (softer layer, improved electrical conductivity) if the $\mathrm{sp}^{2} / \mathrm{sp}^{3}$ ratio is increased [20]. Which bonding site dominates can be controlled with the help of a few parameters such as the plasma conditions, precursor gas, amount of hydrogen [11,19-22], or the layer thickness itself [23-26]. It should also be noted that this change in the chemical composition of the coating has a direct influence on the wettability of the surface [27].

For these layers, however, the strength of their connection with the base material is important. If this is not sufficient, the layer can be easily detached from the material. The more pronounced the interlayer, the better the bond. The interlayer is a mixed phase of base polymer and the deposited layer [28]. The thickness varies between a few $\mathrm{nm}$ (e.g., POM), which results in only a low degree of binding and easy layer removal, and several tens of $\mathrm{nm}$ as for HDPE, leading to a strong connection of the layer with the base material [14,16,23]. Additionally, for thicker layers, the effect of dehydrogenation occurs. Here, hydrogen is removed from the layer and the content of $\mathrm{sp}^{3}$-bonded carbon is reduced in favor of increasing $\mathrm{sp}^{2}$ content [14-16].

These layers can be deposited by a wide variety of techniques, including magnetron sputtering, ion beam deposition or, as in the case of the films analyzed in this work, by means of radio frequency plasma enhanced chemical vapor deposition (RFPECVD) $[11,14,20,28]$. A major advantage is that this technique can also be used to coat polymeric substrates, which are usually non-conductive and require low process temperatures $[13,20]$

In the present study, a-C:H layers of variable thickness were deposited on the polymer polyamide 6 (PA6). This was realized by RF-PECVD technique with an acetylene plasma. The surface morphology of these deposited carbon layers was investigated ex situ by atomic force microscopy (AFM) and scanning electron microscopy (SEM). Diffusive reflectance infrared Fourier transform (DRIFT) and surface sensitive X-ray-based techniques such as near-edge X-ray absorption fine structure (NEXAFS) and X-ray photoelectron spectroscopy (XPS) were used to study the chemical composition of the deposited layers. In addition, contact angle (CA) measurements were performed to evaluate the relationship between $\mathrm{sp}^{2} / \mathrm{sp}^{3}$ ratios and macroscopic physical aspects.

\section{Materials and Methods}

\subsection{Sample Preparation and Coating Process}

The polyamide 6 plates (thickness $1 \mathrm{~mm}$ ) used in this study were delivered by Goodfellow (Bad Nauheim, Germany) and of industrial quality. Stamped samples of PA6 (Ø $10 \mathrm{~mm}$ ) were ultrasonically cleaned with isopropanol, dried at ambient conditions, attached on an aluminum sample holder, and positioned in front of the plasma source (fixed distance $275 \mathrm{~mm}$ ). The generation of the plasma in a vacuum chamber is realized with a high-frequency (RF, $13.65 \mathrm{MHz}$ ) plasma source (Copra DN 400, CCR GmbH, Troisdorf, Germany) [28]. The coating process itself is described in detail elsewhere [26]. In brief: First, there was a 10 min pretreatment with $\mathrm{O}_{2}$ plasma (sample cleaning and surface activation). Second, exposure to $\mathrm{C}_{2} \mathrm{H}_{2}$ plasma for a-C:H layer deposition, where the thickness can be controlled by varying the coating time [14-16,29]. During the entire plasma process, the temperature of the samples did not exceed $40^{\circ}$ at any time [29]. Thereby, a-C:H layer thicknesses from $0 \mathrm{~nm}\left(\mathrm{O}_{2}\right.$-treated sample) up to $2000 \mathrm{~nm}$ (deposition rate $10 \mathrm{~nm} / \mathrm{min}$ [29]) were generated. Below a layer thickness of $100 \mathrm{~nm}$, coatings were realized in $10 \mathrm{~nm}$ steps to analyze the initial a-C:H layer growth. For higher thicknesses, steps of 50, 100, and finally $250 \mathrm{~nm}$ between 1000 to $2000 \mathrm{~nm}$ were chosen. To determine the deposited a-C:H thickness with a profilometer (Dektak 3, Veeco Instruments Inc., Plainview, NY, USA), half covered silicon wafers were used [26]. 


\subsection{Surface Morphology}

The surface morphology was identified using scanning electron microscopy (SEM515, Phillips, 7 kV, WD 20 mm, FEI Company, Amsterdam, The Netherlands) for a more macroscopic overview and atomic force microscopy (AFM, Omicron nanoTechnology $\mathrm{GmbH}$, Taunusstein, Germany) for a detailed mapping. For SEM it was necessary to apply gold (7-10 nm thick) to the samples to increase their conductivity and thus protect them from charging effects and electron beam damage. Both the homogeneity of the sample surfaces and the accuracy of the measurements were provided by recording at least three distinct surface sites. The AFM was operated in contact mode with standard silicon nitride PNP-TR cantilevers (NanoAndMore GmbH, Wetzlar, Germany) at ambient conditions. Cellulose acetate replica (Pelco, 607-AFM) with a 2.160 lines $/ \mathrm{mm}$ waffle pattern diffraction grating were measured regularly to avoid tip sample convolution and tip blending. Recordings at three different sites ensured that the measurements were performed correctly and that no image errors occurred. Image analysis (SPIP version 4.6.1, Image Metrology A/S, Hørsholm, Denmark) was conducted according to the following steps: LMS fit of grade 4 for plane-correction; a median filter for reducing the worst horizontal noise; reduction of the low frequency noise by using a convolution smooth low pass filter and a convolution smooth mean filter; removing long waves and filtering out values outside of the color boundaries [29]. To investigate the sample surface wettability, contact angle (CA) measurements were performed using an OCA15EC (Dataphysics Instruments $\mathrm{GmbH}$, Filderstadt, Germany) at ambient conditions: sessile drop technique, $1 \mu \mathrm{L}$ water (HPLC grade, CHEMSOLUTE ${ }^{\circledR}$, Th. Geyer GmbH \& Co. KG, Renningen, Germany) at five different sites, and resulting CA averaging. This way, the homogeneity of the sample surface could be additionally checked.

\subsection{Infrared Spectroscopy}

For the chemical composition of each sample surface, diffuse reflectance infrared Fourier transform (DRIFT) measurements were performed at ambient conditions. For this purpose, a Shimadzu Fourier transform spectrometer (IRPrestige-21, Shimadzu Corporation, Kyoto, Japan) equipped with the diffuse reflectance measuring apparatus DRS-8000 was used [30,31]. Measurements were repeated at three different surface sites to ensure surface homogeneity. For each sample, two spectra were recorded: a spectral survey (500-4000 $\mathrm{cm}^{-1}$ resolution: 4 wavenumbers, 100 repetitions) followed by a detailed recording for the $\mathrm{C}-\mathrm{H}$ stretching region $[26,32]\left(2800-3100 \mathrm{~cm}^{-1}\right.$ resolution: 1 wavenumber, 300 repetitions). The overall reference for the a-C:H data analysis is the $\mathrm{O}_{2}$ plasma-cleaned PA6 sample, as each one has been $\mathrm{O}_{2}$ plasma pretreated. FTIR Control Software (software version 1.30, Shimadzu Corporation, Kyoto, Japan) was used for a two-step spectral evaluation: a multipoint baseline insertion with the integrated manipulation tool and afterwards a smoothing manipulation.

\subsection{X-ray Spectroscopy}

The X-ray photoelectron spectroscopy (XPS) and near-edge X-ray absorption fine structure (NEXAFS) measurements were performed at the synchrotron BESSY, HelmholtzZentrum Berlin, during the low-alpha phase and used as supportive studies of the carbon bond state on the surface. The used HE-SGM beamline system is described elsewhere [33]. To prevent charge-induced effects on the sample surface it is additionally equipped with a flood gun.

During the XPS measurements, a full spectrum (700 to $0 \mathrm{eV}$ ) was first recorded. This survey provides an overview of the entire chemical surface composition. The $\mathrm{C} 1 \mathrm{~s}$ peak was examined to analyze the different binding states of the carbon atoms. These measurements were performed at least at two different sample sites to check reproducibility, homogeneity, and the stability of the deposited a-C:H layers. For the analysis of the received spectra and the deconvolution of the C1s spectra, the commercially available software CasaXPS (software version 2.3.18, Casa Software Ltd., Teignmouth, UK) was used. The percentages 
of $\mathrm{sp}^{2}, \mathrm{sp}^{3}, \mathrm{C}-\mathrm{O}$, and $\mathrm{C}=\mathrm{O}$ bonds in the total $\mathrm{C} 1$ s peak were identified, where $\mathrm{C}-\mathrm{O}$ bonds were evaluated as $\mathrm{sp}^{3}$ bond and the $\mathrm{C}=\mathrm{O}$ bond as $\mathrm{sp}^{2}$-bonded carbon, and related to the corresponding thicknesses. To compensate for static charges, the scale of the binding energy was corrected in the evaluations. The C1s peak was set to a value of $284.8 \mathrm{eV}$ [33].

The $\mathrm{C}$ as well as the $\mathrm{O} \mathrm{K}$-edges were recorded with NEXAFS. For the $\mathrm{C} \mathrm{K}$ edge, measurements were taken on at least two different surface sites to ensure accuracy. $\mathrm{O}$ $\mathrm{K}$-edges were recorded to check the presence or absence of oxygen. All measurements were performed in partial electron yield (PEY) in which a counter voltage is applied. In this way, the measurement electronics are not reached by all the electrons leaving the material, meaning it is very surface sensitive [34]. Detector and sample geometry followed an incidence angle of $55^{\circ}$. The C K-edges were analyzed using Origin 8.1 commercial software. For the analysis according to Watts et al. [35], it was necessary to first normalize the spectra and then adjust them to the decreasing ring current present at the BESSY experimental station. Subsequently, a correction with a previously measured gold edge was performed to eliminate a possible contamination of the grid. Further analysis was performed using a self-written peak evaluation program combined with Origin 8.1 software.

\section{Results}

\subsection{Surface Morphology}

First, SEM images are discussed to get an overview of the layer condition. Figure 1 shows the reference sample (Figure 1a), the $\mathrm{O}_{2}$ plasma-treated sample (Figure $1 \mathrm{~b}$ ), and a-C:H coated samples up to a layer thickness of $100 \mathrm{~nm}$ (Figure 1c-1). Thicker layers are displayed in Figure 2.

The reference sample of PA6 (Figure 1a) is strongly structured and shows many scratches, which are due to the production process. Additionally, some minor impurities in the form of particles are visible. The $\mathrm{O}_{2}$ plasma-treated sample (Figure $1 \mathrm{~b}$ ) is smoother and has fewer scratches. In addition, there are less dirt particles on the surface. With the application of a-C:H layers of increasing thickness starting at $10 \mathrm{~nm}$ (Figure 1c-l) the scratches become weaker as they are covered with the a-C:H layer. The deposited layer is closed and appears homogeneous. On the $50 \mathrm{~nm}$ sample (Figure 1g) three black stripes are visible. Here, the gold layer applied for the SEM measurements is probably damaged, which leads to charging effects and thus to a darker appearance. With increasing thickness, the scratches of the base material are still visible, but the layer appears closed overall and adheres well.

In Figure 2a-f, the up to $2 \mu \mathrm{m}$ thick a-C:H layers deposited on PA6 are shown. With $300 \mathrm{~nm}$ (Figure 2a) the surface of the layer is homogeneous and closed. The scratches are further attenuated. This behavior continues up to $1500 \mathrm{~nm}$ (Figure $2 \mathrm{~b}-\mathrm{d}$ ), but when the $\mathrm{a}-\mathrm{C}: \mathrm{H}$ layer reaches $1750 \mathrm{~nm}$ (Figure 2e), the layer breaks up. The layer failure continues with the PA6 sample coated with $2000 \mathrm{~nm}$ (Figure 2f).

For a detailed investigation of the surface morphology, high-resolution AFM measurements were performed. Figure 3a shows the surface morphology of raw PA6 (reference sample), the PA6 cleaned with oxygen plasma (Figure $3 b$ ), and PA6 covered with a-C:H layers from 10 to $100 \mathrm{~nm}$ (Figure $3 \mathrm{c}-\mathrm{h}$ ) in ascending order. The measured area has a size of $5 \mu \mathrm{m} \times 5 \mu \mathrm{m}$, the roughness values for the AFM measurements (raw PA6 to $2000 \mathrm{~nm}$ a-C:H@PA6) are shown in Table 1. The roughness $R_{\mathrm{q}}$ is in the interval of $5.12 \pm 0.55 \mathrm{~nm}$ (1000 nm deposition) and $9.20 \pm 0.11 \mathrm{~nm}(100 \mathrm{~nm}$ deposition) for all samples measured resulting in a relatively smooth layer. For the raw and the $\mathrm{O}_{2}$ plasma-treated PA6 sample, the surface is bumpy and shows some scratches, which could be a result of the manufacturing process. Some particles which are visible on the AFM image can be dust or dirt. These are unavoidable due to the industrial production of the samples and the prevalent environment there. For the AFM images, the surface of the oxygen-treated sample (Figure $3 b$ ) appears to be a little more roughened compared to the raw material $\left(R_{\mathrm{q}}\right.$ of $6.81 \pm 1.10 \mathrm{~nm}$ compared to $6.21 \pm 0.68 \mathrm{~nm}$ ), which is most likely caused by the oxygen bombardment. Additionally, some scratches are still visible. With the deposition of a $10 \mathrm{~nm}$ a-C:H layer on PA6 
(Figure 3c), the surface is covered by small, unstructured, grain-like particles resulting in a raised $R_{\mathrm{q}}$ value of $8.22 \pm 1.31 \mathrm{~nm}$. This more uneven morphology of the coating decreases with increasing a-C:H layer thickness and an overall more even layer is formed, which has a defined grain-like morphology. This starts with a thickness of $40 \mathrm{~nm}$. The beginning growth of a homogeneous grain structure resp. layer represents the completion of the interlayer phase [14]. Here, the roughness is $9.04 \pm 0.92 \mathrm{~nm}$ and nearly at its maximum value. The interlayer is a mixed phase of polymer and a-C:H layer, whose thickness can be estimated to $40 \mathrm{~nm}$ by the current AFM investigations. The start of the normal layer growth at $50 \mathrm{~nm}$ a-C:H thickness is accompanied by a lower $R_{\mathrm{q}}(8.73 \pm 0.58 \mathrm{~nm})$. The scratches already visible on raw PA6 are still visible on thinner layers, especially on a-C:H layers of 20,30, and $100 \mathrm{~nm}$ (Figure 3d,e,h). This behavior is similar to that of such a-C:H layers on high-density polyethylene (HDPE), which have already been investigated by Catena et al. [14].
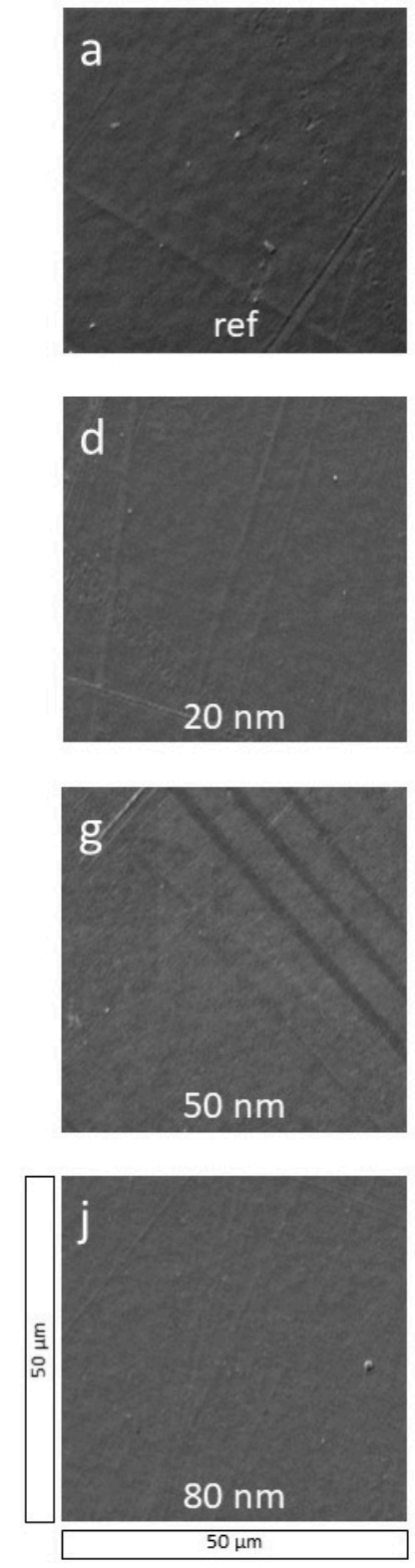
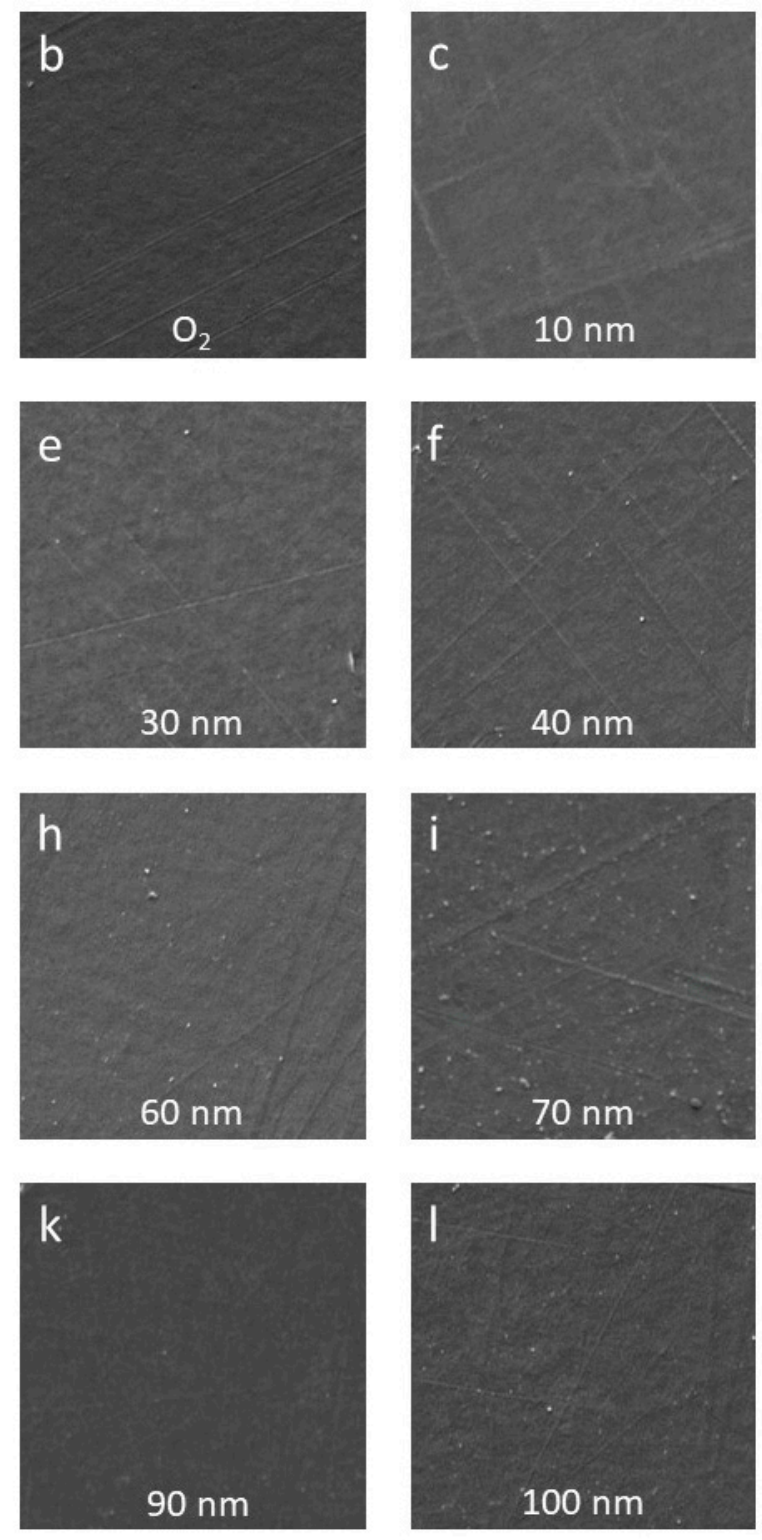

Figure 1. SEM surface images of PA6 samples coated with thin a-C:H layers from 10 to $100 \mathrm{~nm}$ in $10 \mathrm{~nm}$ steps (c-1). Additionally, the reference (a) and the $\mathrm{O}_{2}$ plasma-treated PA6 sample (b) are added. 

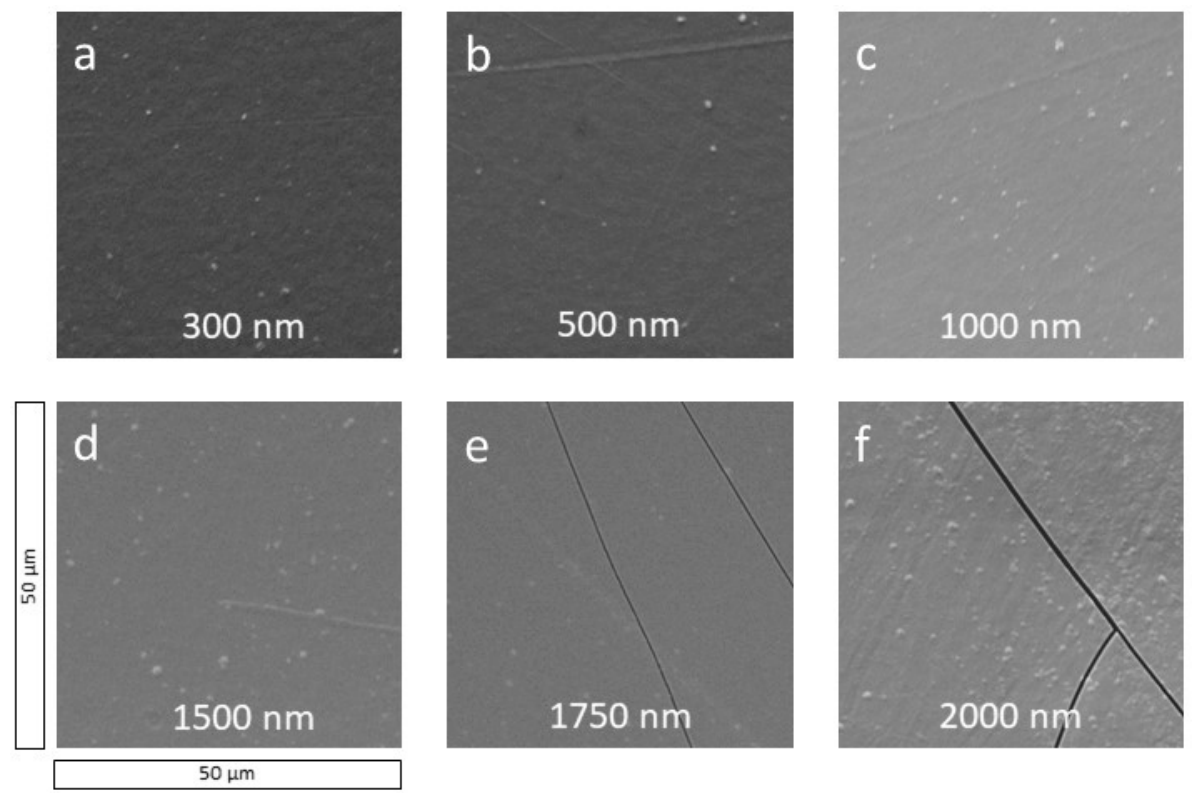

Figure 2. SEM analysis of thick a-C:H layers on PA6 (a-f). Thickness varies from (a) 300 to (f) $2000 \mathrm{~nm}$, arranged in increasing layer thickness.

Table 1. AFM roughness values $R_{\mathrm{a}}$ and $R_{\mathrm{q}}$ for the reference, the $\mathrm{O}_{2}$ plasma-treated, and with PA6 samples coated with thin a-C:H layers of various thickness.

\begin{tabular}{ccc}
\hline Sample & $\boldsymbol{R}_{\mathbf{a}}[\mathbf{n m}]$ & $\boldsymbol{R}_{\mathbf{q}}[\mathbf{n m}]$ \\
\hline Reference & $4.74 \pm 0.37$ & $6.21 \pm 0.68$ \\
$\mathrm{O}_{2}$ & $5.25 \pm 0.76$ & $6.81 \pm 1.10$ \\
$10 \mathrm{~nm}$ & $6.25 \pm 1.05$ & $8.22 \pm 1.31$ \\
$20 \mathrm{~nm}$ & $6.52 \pm 0.25$ & $8.25 \pm 0.40$ \\
$30 \mathrm{~nm}$ & $5.98 \pm 0.04$ & $7.61 \pm 0.27$ \\
$40 \mathrm{~nm}$ & $6.86 \pm 0.49$ & $9.04 \pm 0.92$ \\
$50 \mathrm{~nm}$ & $6.53 \pm 0.44$ & $8.73 \pm 0.58$ \\
$100 \mathrm{~nm}$ & $6.73 \pm 0.02$ & $9.20 \pm 0.11$ \\
$300 \mathrm{~nm}$ & $5.15 \pm 0.11$ & $6.74 \pm 0.27$ \\
$500 \mathrm{~nm}$ & $4.81 \pm 0.62$ & $6.14 \pm 0.91$ \\
$1000 \mathrm{~nm}$ & $4.86 \pm 0.12$ & $6.28 \pm 0.18$ \\
$1500 \mathrm{~nm}$ & $5.09 \pm 1.90$ & $6.63 \pm 2.12$ \\
$2000 \mathrm{~nm}$ & $3.98 \pm 0.29$ & $5.12 \pm 0.55$ \\
\hline
\end{tabular}

Figure 4 shows the AFM images of the deposition of thicker a-C:H layers from 300 up to $2000 \mathrm{~nm}$. The homogeneous grain structure, which became observable for the thin layers beginning at $40 \mathrm{~nm}$, continues for the $300 \mathrm{~nm}$ layer (Figure $4 \mathrm{a}$ ). With a thickness of $500 \mathrm{~nm}$ (Figure $4 \mathrm{~b}$ ) the majority of the grains becomes smaller compared to the grains of the $300 \mathrm{~nm}$ layer $\left(R_{\mathrm{q}}\right.$ of $6.14 \pm 0.91 \mathrm{~nm}$ compared to $\left.6.74 \pm 0.27 \mathrm{~nm}\right)$. This may be a consequence of a new grain layer starting on top of the previous closed one at a lower thickness. The AFM images for 1000, 1500, and $2000 \mathrm{~nm}$ (Figure 4c-e) show smoother grains than before, resulting in the lowest surface roughness of $5.12 \pm 0.55 \mathrm{~nm}$ at $2000 \mathrm{~nm}$ a-C:H layer thickness. They become more regularly spaced, but differences in grain size remain constant. The AFM images confirm the homogeneous surface coating of the PA6 samples with a-C:H for higher layer thicknesses, as already indicated by the SEM (Figure 2). For thin layers, it could also be determined that this homogeneous layer growth starts only at about $40 \mathrm{~nm}$ with the completion of the interlayer. This could not be detected on the SEM due to its lower resolution. However, with SEM it was possible to show the layer failure at higher layer thicknesses which, of course, is poorly detectable in AFM. Here, both techniques complement each other well. 

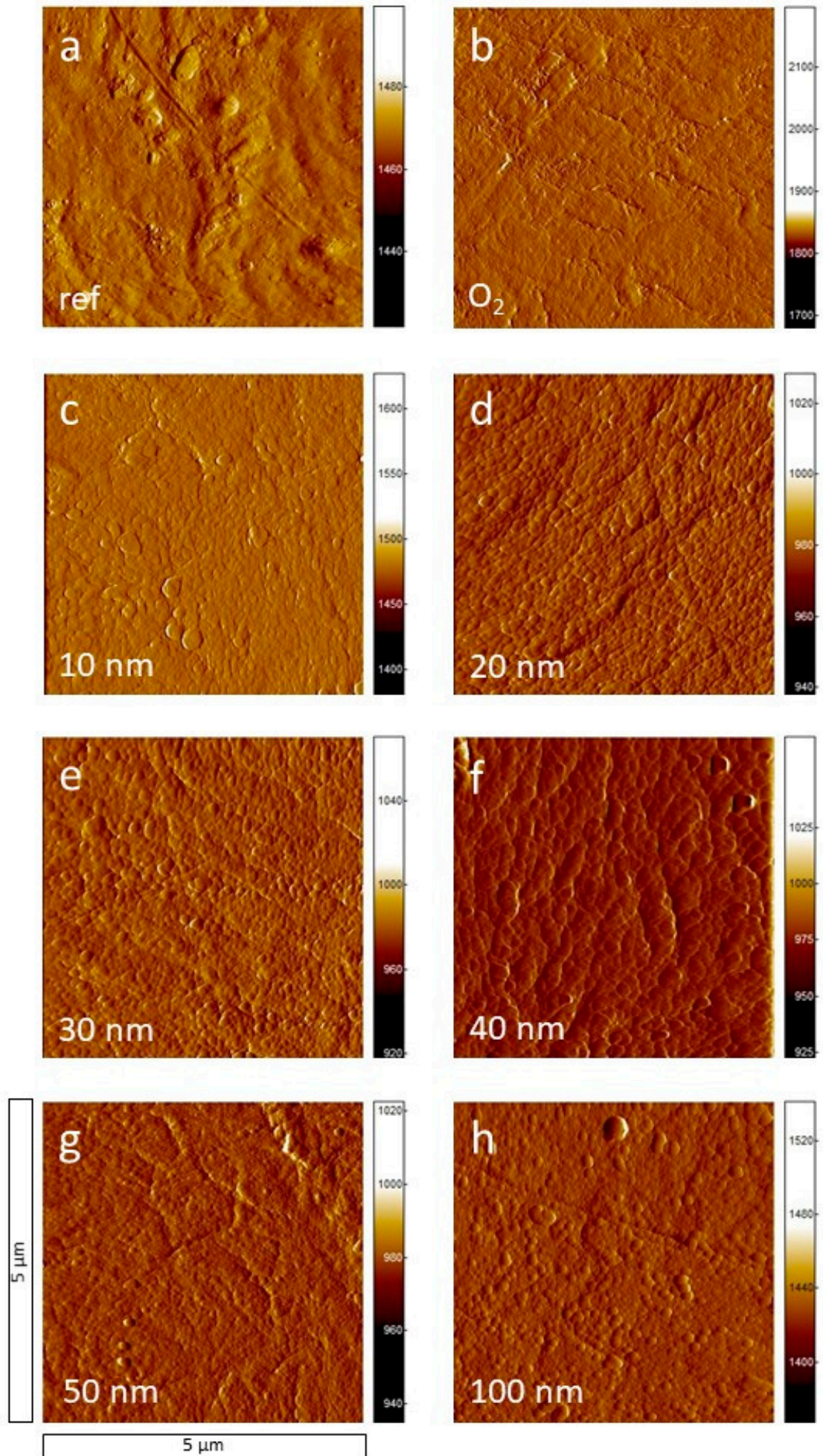

Figure 3. AFM images of the raw PA6 (a), the $\mathrm{O}_{2}$ plasma-treated PA6 (b) samples, and PA6 samples coated with thin a-C:H layers of various thickness (10 to $100 \mathrm{~nm}, \mathbf{c}-\mathbf{h})$. The image size is $5 \mu \mathrm{m} \times 5 \mu \mathrm{m}$. 

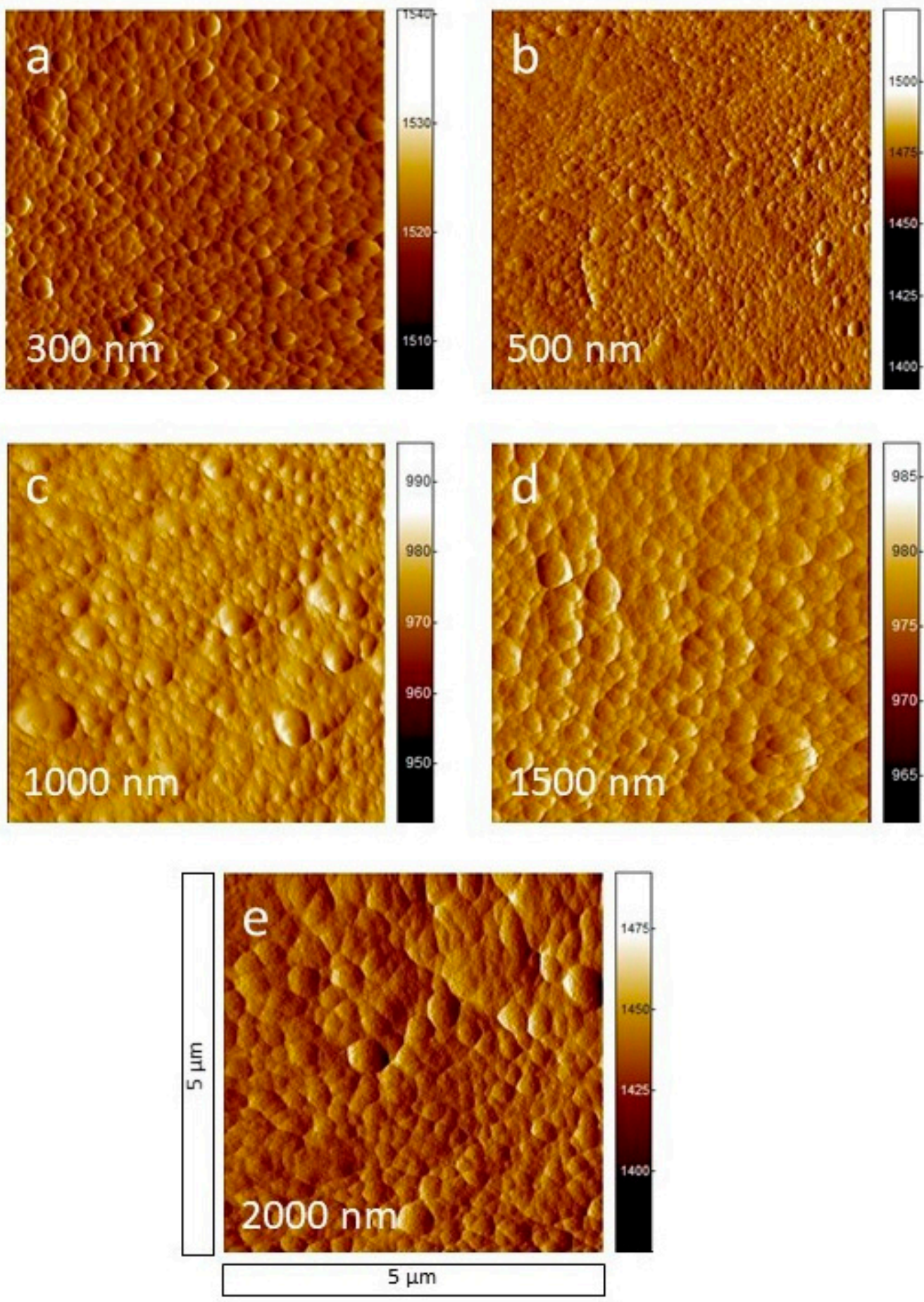

Figure 4. AFM measurements for PA6 samples (a-e) coated with thick a-C:H layers from (a) 300 up to (e) $2000 \mathrm{~nm}$. The image size is $5 \mu \mathrm{m} \times 5 \mu \mathrm{m}$.

CA measurements were performed for further analysis of the surface characteristics. The wettability of the surface and thus the resulting CAs of the investigated a-C:H layers are influenced by three factors: (I) the morphology of the surface [36-38]; (II) the different carbon hybridization states on the surface [18,21,39-41]; and (III) the existing chemical bonds [42-45]. A detailed description is summarized in a previous paper by some of the authors [26].

For a better overview, the CA evaluation is divided into two diagrams. Figure 5 shows the CAs obtained for the series of a-C:H layers from 10 to $100 \mathrm{~nm}$ deposited on PA6. Additionally, the $\mathrm{CA}$ of the raw and e $\mathrm{O}_{2}$ plasma-cleaned PA6 are shown. The 
plasma-cleaned sample is used here as the reference since all a-C:H deposited samples were previously $\mathrm{O}_{2}$ plasma cleaned. For the raw PA6 polymer the $\mathrm{CA}$ is $74^{\circ}$ and within the limits of the literature values [46]. With $\mathrm{O}_{2}$ plasma treatment, the angle decreases to $66^{\circ}$. As discussed earlier, this is due to the presence of functional oxygen groups. The surface becomes more hydrophilic and the CA decreases. With the application of $10 \mathrm{~nm}$ a-C:H layer, the CA drops rapidly to $58^{\circ}$. This behavior continues until the $20 \mathrm{~nm}$ deposition, where the lowest measured value of $44^{\circ}$ is reached for the present series. If the film thickness is increased to $30 \mathrm{~nm}$, the CA changes to $72^{\circ}$. Up to a layer thickness of $60 \mathrm{~nm}$, the CA varies between $68^{\circ}$ and $76^{\circ}$, meaning it remains relatively constant within the error margins, even for the relatively large error at $50 \mathrm{~nm}$. This also indicates the completion of the interlayer phase in the 30 to $40 \mathrm{~nm}$ region, since a new growth phase starts. With a layer thickness of $80 \mathrm{~nm}$ the CA decreases again sharply to $57^{\circ}$ before returning to $75^{\circ}$ at $90 \mathrm{~nm}$. In summary, for the thin film depositions (10 to $100 \mathrm{~nm}$, Figure 5) according to the CAs, an overall similar film is obtained, with few exceptions only after reaching $30 \mathrm{~nm}$, despite continued growth resp. increase of layer thickness. For 30 to $100 \mathrm{~nm}$ a-C:H and the raw PA6, with the exception of $80 \mathrm{~nm}$ deposition, the CA values are comparatively high, which is associated with a $\mathrm{sp}^{2}$-like carbon hybridization. The CA of the 10, 20, and $80 \mathrm{~nm}$ depositions are below $60^{\circ}$, which indicates a more $\mathrm{sp}^{3}$-like hybridization of the carbon atoms.

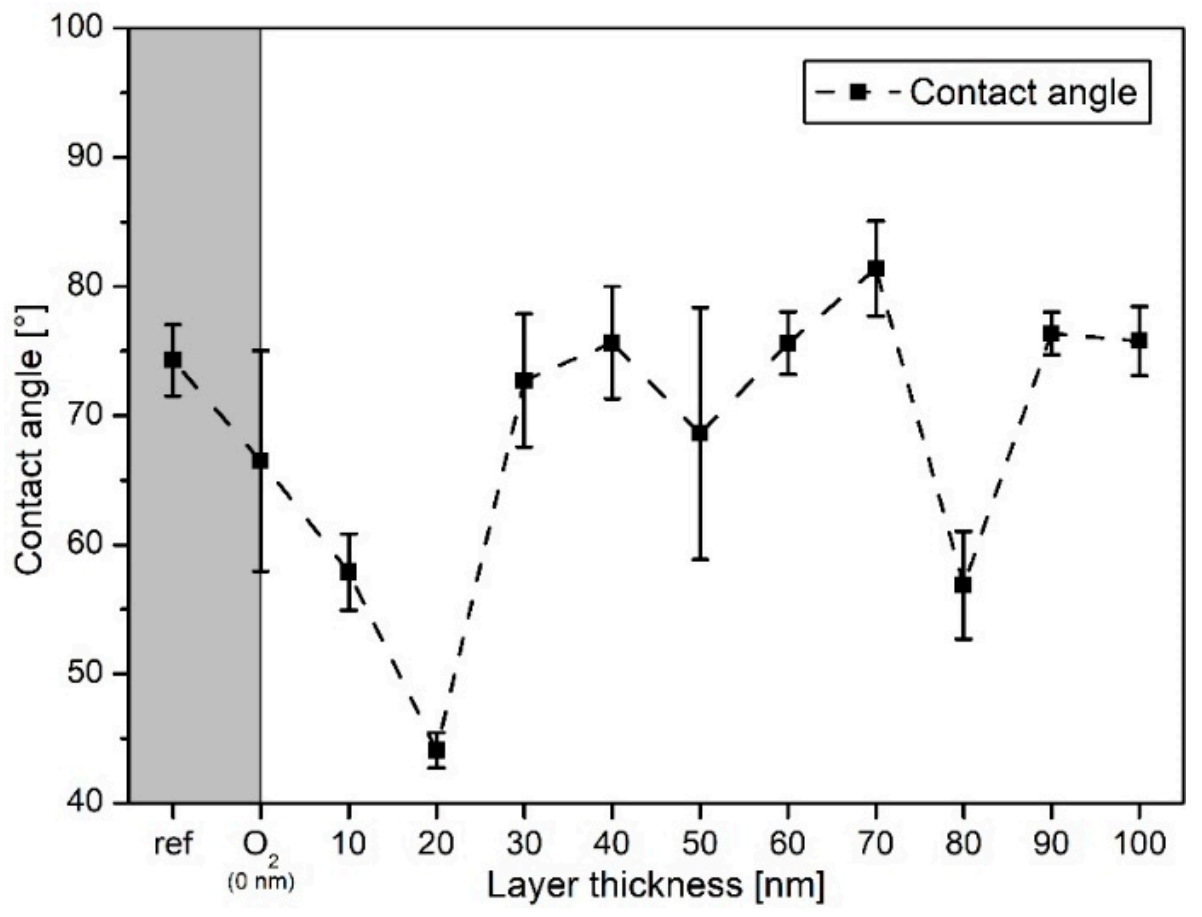

Figure 5. Contact angle measurements for the PA6 samples: shown are raw and $\mathrm{O}_{2}$ plasma-treated PA6 as well as thin a-C:H layers up to $100 \mathrm{~nm}$ (the dashed line only indicates the trend).

The gray box depicts values for the raw polymer and the $\mathrm{O}_{2}$ plasma-pretreated sample. The layer thickness of $0 \mathrm{~nm}$ is depicted by the $\mathrm{O}_{2}$ sample.

Figure 6 shows the $\mathrm{CA}$ measurements for the thicker a-C:H depositions from 100 to $2000 \mathrm{~nm}$ on PA6. For the layers between 100 and $800 \mathrm{~nm}$, the CAs alternate between $75^{\circ}$ and $82^{\circ}$. With reaching a layer thickness of $900 \mathrm{~nm}$, the CA decreases to $65^{\circ}$, but recovers at $1250 \mathrm{~nm}$ within $78^{\circ}$ and $81^{\circ}$ until $1750 \mathrm{~nm}$. At $2000 \mathrm{~nm}$, the CA decreases again. The temporarily strong decrease in CAs between 800 and $1250 \mathrm{~nm}$ may indicate a change of the hybridization state to a more $\mathrm{sp}^{3}$-dominated network. It is also conceivable that dehydrogenation of the layer occurs right after, resulting in a higher contact angle due to the higher amount of $\mathrm{sp}^{2}$-bound carbon, i.e., a reduced proportion of hydrogen in the bonds present. This has already been proven for HDPE in this a-C:H thickness 
range $[14,23]$. The error of the CA measurements is relatively small in most cases, which suggests a flat, homogeneous surface, as already visible in SEM (Figures 1 and 2) and AFM (Figures 3 and 4). For the layers above $1750 \mathrm{~nm}$, which were visibly broken in SEM (Figure 2e,f), a larger error was to be expected due to the non-closed surface. The relatively small error is possibly due to the limited amount of cracks. A change in the bonding ratio of the carbon atoms and the CAs, as in other materials before, could not be observed [24,25].

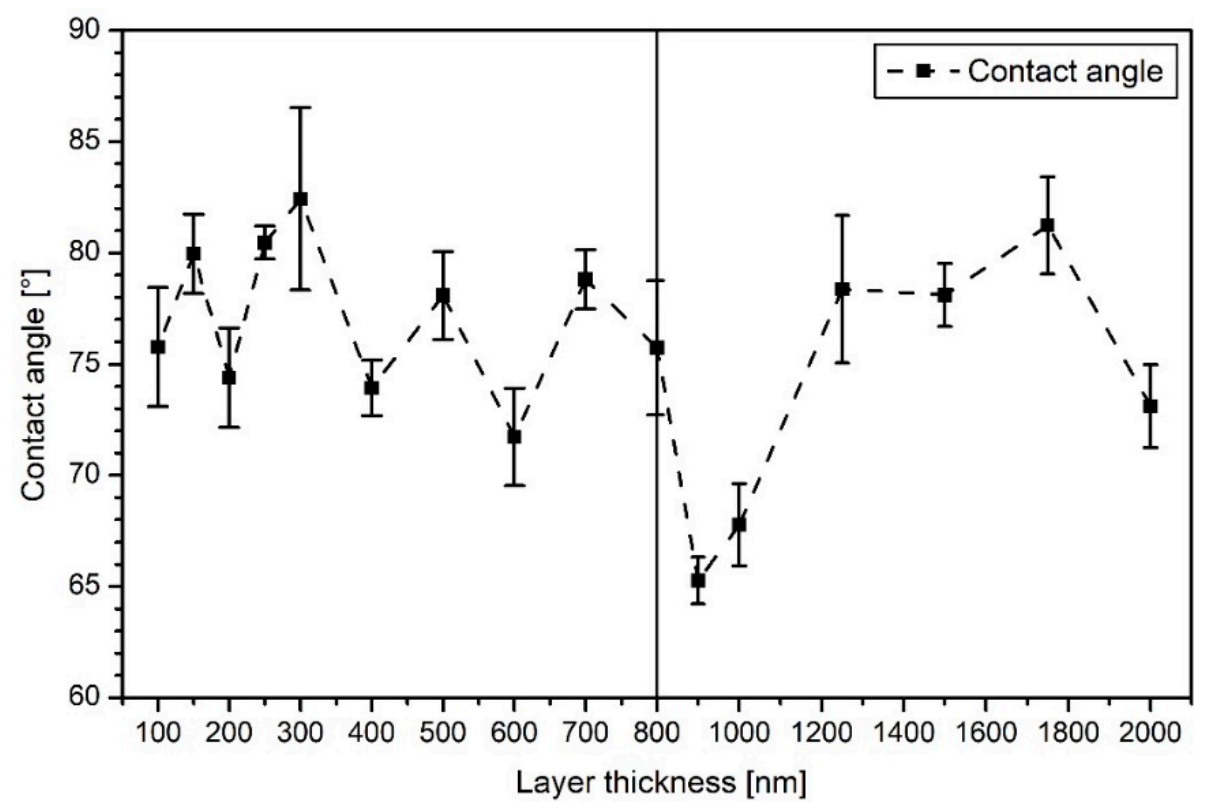

Figure 6. Contact angles of amorphous hydrogenated carbon $(\mathrm{a}-\mathrm{C}: \mathrm{H})$ coatings of layer thicknesses from 100 to $2000 \mathrm{~nm}$ on PA6 samples (the dashed line only indicates a trend).

\subsection{Infrared Spectroscopy}

DRIFT spectroscopy allows examining differences in the chemical composition of the aC:H layers deposited on the PA6 samples as a function of their specific thickness. In particular, the measurements presented here provide information on the various $\mathrm{sp}^{2}$ and $\mathrm{sp}^{3}$ bonds of the carbon atoms present in the layers. The results of the DRIFT spectra in Figures 7 and 8 are evaluated on the basis of own results and those of other groups $[15,16,47,48]$. The $\mathrm{O}_{2}$ plasma-treated PA6 is used as a reference ("background") for the samples investigated here since all a-C:H layers are deposited on a previously oxygen-treated PA6 surface.

Figures 7 and 8 show the corresponding spectra in ascending order plotted in arbitrary units (arb. u.). For a better overview, the obtained results are shown separately: the raw PA6 sample and the thinner a-C:H layers from 10 to $100 \mathrm{~nm}$ are plotted in Figure 7, the thicker layers from 300 to $2000 \mathrm{~nm}$ in Figure 8. Thinner layers were coated and measured in $10 \mathrm{~nm}$ steps due to special interest in the interlayer formation taking place in this region. Figure 7 shows that a total of eight different oscillations of carbon bonds occur for the thin layers. It is noticeable that the peak orientation according to the PA6 sample treated with $\mathrm{O}_{2}$ plasma contains more $\mathrm{sp}^{3}\left(\mathrm{sp}^{3} \mathrm{CH}_{3} \underline{a}=\right.$ asymmetric at $2952 \mathrm{~cm}^{-1}, \mathrm{sp}^{3} \mathrm{CH}_{2} \underline{a}$ is at $2917 \mathrm{~cm}^{-1}$, and $\mathrm{sp}^{3} \mathrm{CH}_{2} \underline{s}=$ symmetric at $\left.2847 \mathrm{~cm}^{-1}[47,48]\right)$ to both the raw polymer and all a-C:H layers. The lower proportion of $\mathrm{sp}^{3}$ bonds on the surface of the raw polymer is due to impurities that have settled there and been removed by the oxygen plasma. In addition, only two of the bonds measured are absorption oscillations: the comparatively dominant $\mathrm{sp}^{2} \mathrm{CH}_{2} \underline{s}$ oscillation at $2974 \mathrm{~cm}^{-1}$ and the $\mathrm{sp}^{3} \mathrm{CH}_{3} \underline{s}$ at $2871 \mathrm{~cm}^{-1}$ [48], which is relatively weak. For the layers, this means that the carbon is mostly $\mathrm{sp}^{2}$ bounded. Vibrations for $\mathrm{sp}^{2} \mathrm{CH}$ olefinic $\left(3032 \mathrm{~cm}^{-1}\right.$ [48]) are only visible for the 10 and $80 \mathrm{~nm}$ a-C:H layer, and they are comparatively weak and will not be further discussed. 


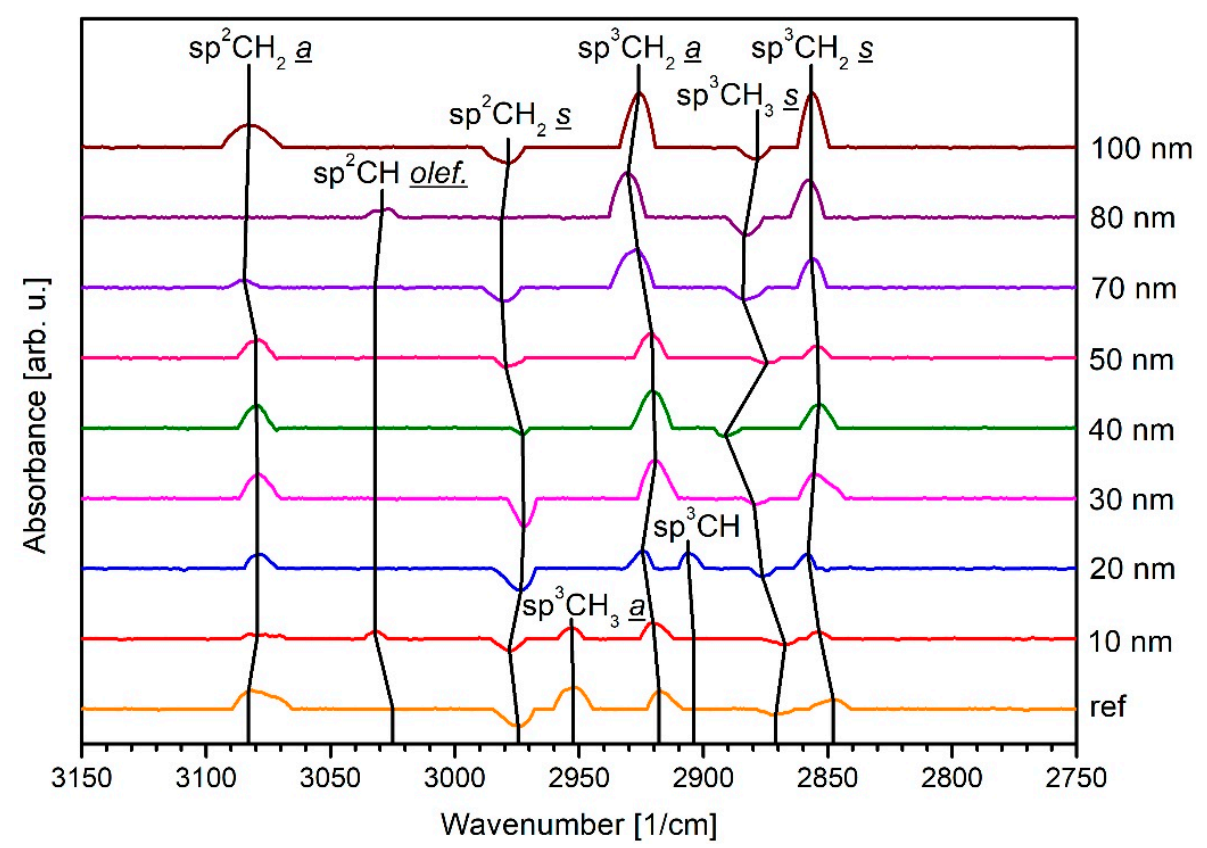

Figure 7. DRIFT spectra of the analyzed PA6 samples coated with thin a-C:H up to $100 \mathrm{~nm}$ in $10 \mathrm{~nm}$ steps starting from the $\mathrm{O}_{2}$ plasma-treated reference. The measurement series is applied from below to above with increasing layer thickness.

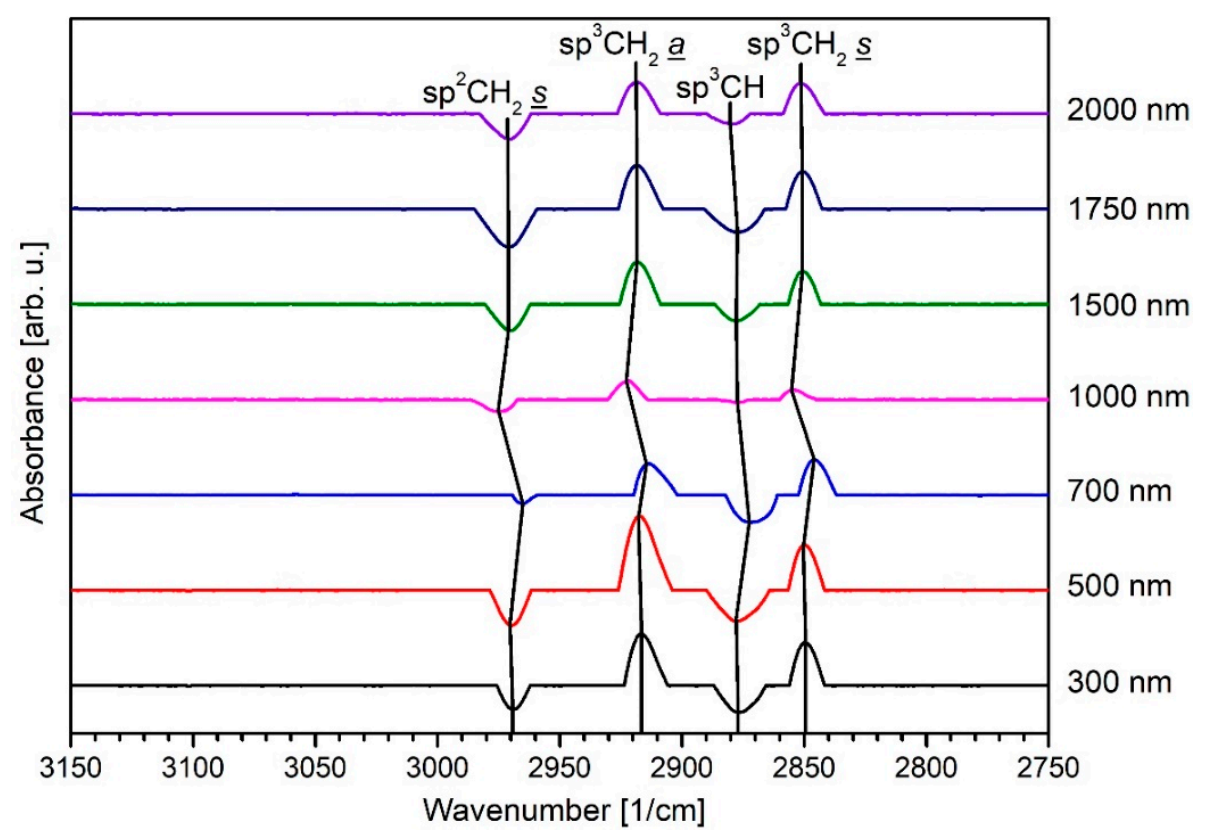

Figure 8. DRIFT spectra for PA6 samples coated with thick a-C:H from 300 to $2000 \mathrm{~nm}$ with increasing layer thickness from below.

The $\mathrm{sp}^{3} \mathrm{CH}_{3} \underline{a}$ peak is also not discussed further, as it is only available for the reference sample and the $10 \mathrm{~nm}$ a-C:H coating. Since this layer thickness corresponds approximately to the measuring depth, signals of the PA6 material are transmitted. In the course of the current coating process, the surface of the a-C:H layer undergoes some chemical changes, which are characterized by peaks of varying intensity. Overall, however, the same bond oscillations are observed for all measured layer thicknesses. A noticeable change as function of film thickness is a significant shift in the peaks, i.e., a slight change of the peak positions. A shift to a larger wave number means, here, a higher $\mathrm{C}-\mathrm{H}$ binding energy. 
This is expressed by a smaller binding distance between the $\mathrm{C}-\mathrm{H}$ atoms [32]. The $\mathrm{sp}^{2} \mathrm{CH}_{2}$ $\underline{a}$ bond shifts to a higher wavenumber at a layer thickness of $80 \mathrm{~nm}$. The $\mathrm{sp}^{2} \mathrm{CH}_{2} \underline{s}$ bond, in contrast, undergoes several shifts. Firstly, during layer growth to $10 \mathrm{~nm}$ to higher wavenumbers, and then returning to the old position when changing to $20 \mathrm{~nm}$. After reaching a layer thickness of $40 \mathrm{~nm}$, the peak shifts again to higher wavenumbers. The $\mathrm{sp}^{3}$ bonds carry out a large number of shifts and change minimally at almost any layer thickness. Changing binding distances, recognizable by frequencies shifting back, indicate a changing in chemical composition. Thus, a chemically very variable environment is present on the surface with $\mathrm{sp}^{2}$-dominated absorption behavior. A large number of wellformed $\mathrm{sp}^{3}$ peaks, which are not absorption peaks, indicate a lower $\mathrm{sp}^{3}$ content compared to the $\mathrm{O}_{2}$ plasma-treated sample and support the statement of $\mathrm{sp}^{2}$ dominated growth for the first $100 \mathrm{~nm}$ layer thickness. A similar behavior has been observed for such a-C:H coatings on other polymers $[15,16,23-26]$.

Figure 8 shows the DRIFT measurements for the thick layers greater than 100 up to $2000 \mathrm{~nm}$ layer thickness. For thicker a-C:H layers on PA6, most of the peaks previously visible for thin layers disappear (compare Figure 7). A total of four oscillations of carbon bonds can be identified. As absorption peaks, the $\mathrm{sp}^{2} \mathrm{CH}_{2} \underline{s}$ and the $\mathrm{sp}^{3} \mathrm{CH}$ peak as well as the oscillations of the symmetric and asymmetric $\mathrm{sp}^{3} \mathrm{CH}_{2}$ bond are also visible. These indicate their presence in the $\mathrm{O}_{2}$-treated sample, but not or only to a relatively small extent in the a-C:H layers. As with the thin layers, all bonds undergo a large number of position shifts, so the surface is chemically very variable. For 300 and $500 \mathrm{~nm}$, the peaks for the $\mathrm{sp}^{2}$ and $\mathrm{sp}^{3}$ oscillation are both well defined. With a change to $700 \mathrm{~nm}$ film thickness, the $\mathrm{sp}^{3} \mathrm{CH}$ bond dominates the absorption peaks. This indicates that with increasing a-C:H layer thickness, more $\mathrm{sp}^{3}$ bonds are formed. These bindings are very strong in comparison to $\mathrm{sp}^{2}$ and $\mathrm{sp}$ bonds, due to their tetrahedral shape [21]. When the $1500 \mathrm{~nm}$ thickness is reached, the $\mathrm{sp}^{3}$ bond weakens and the $\mathrm{sp}^{2}$ bond becomes dominant until $2000 \mathrm{~nm}$. Additionally, with reaching the $1500 \mathrm{~nm}$ a-C:H, all peaks shift back to their values from the beginning. This is an indication of the dehydrogenation of the layer. Hydrogen is released from the carbon $\mathrm{sp}^{3}$ bonds by conversion to $\mathrm{sp}^{2}$ bonds, whose proportion increases. This is in line with the results of the CA measurements which is rising in this film thickness region. Dehydrogenation could already be observed for HDPE for a similar thickness range [14,23].

\subsection{X-ray Spectroscopy}

For further analysis of the chemical composition of the deposited a-C:H layers on PA6, measurements were performed using the X-ray synchrotron-based techniques XPS and NEXAFS. Figure 9 shows the evaluated results for the XPS measurements (for deconvolution results, see Supplementary Material). Here, the $\mathrm{sp}^{2}$ and $\mathrm{sp}^{3}$ bonds are plotted as a function of film thickness. Peak positions were identified using the NIST database and other publications [24,25,49-51]. For a better overview, the graph has been separated into Figure 9A for thin films from 0 to $100 \mathrm{~nm}$ (including the raw $\mathrm{PA} 6$ and $\mathrm{O}_{2}$ plasma-treated sample) and Figure 9B for thick films from 100 to $2000 \mathrm{~nm}$. A more detailed analysis of the thinner layers was carried out to investigate the formation of the interlayer, which is a mixture of base polymer and the a-C:H layer. 


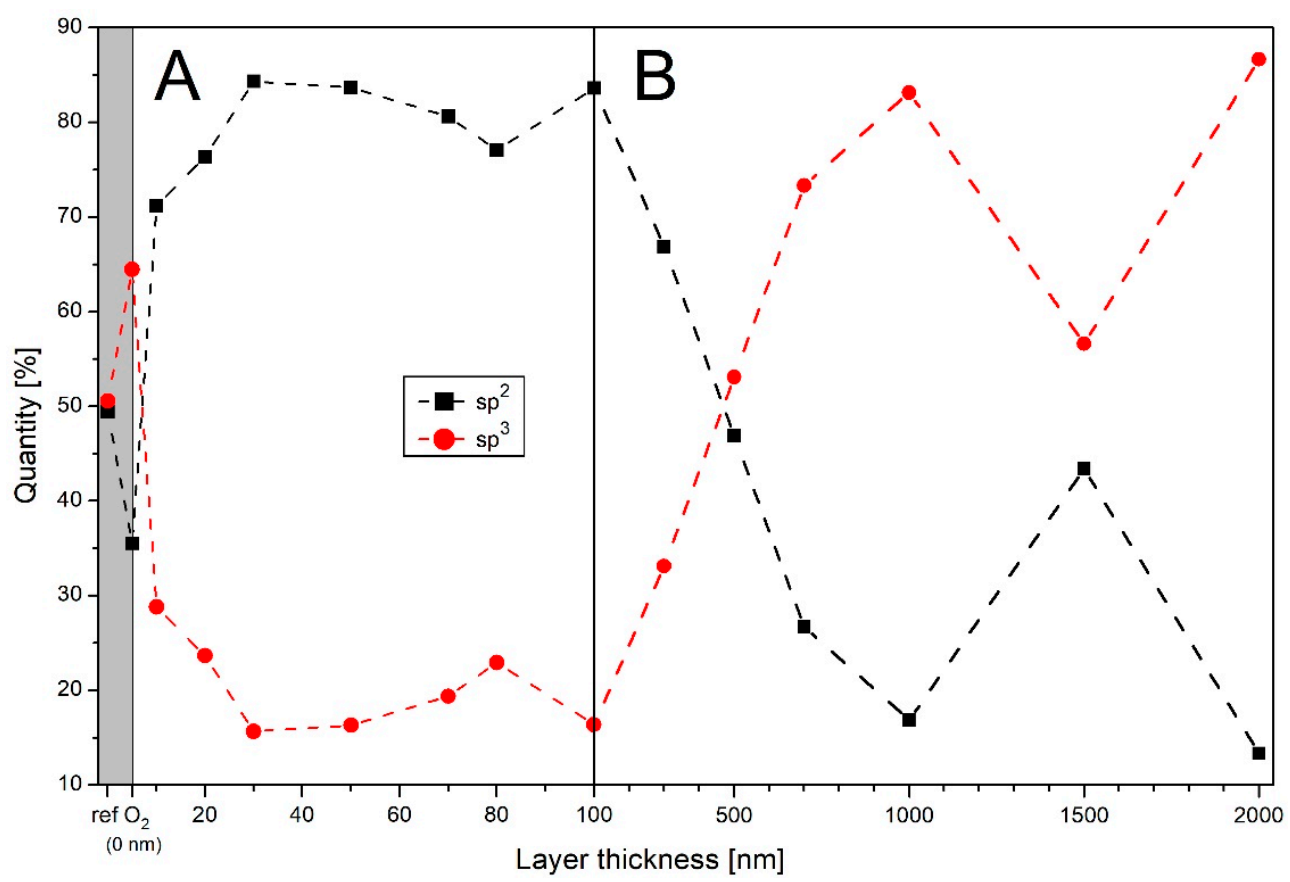

Figure 9. XPS measurements for PA6 coated with a-C:H layers of various thickness. The content of the sp ${ }^{2}$ (black squares) and $\mathrm{sp}^{3}$ (red circles) bound carbon are plotted against layer thickness: (A) thin layers from raw PA6 (ref) and $\mathrm{O}_{2}$-cleaned material (represents a layer thickness of $0 \mathrm{~nm}$ ) to $100 \mathrm{~nm}$ and (B) thicker layers up to $2000 \mathrm{~nm}$ (the dashed line only indicates a trend). The gray box indicates the region before a-C:H coating ( $0 \mathrm{~nm}$ layer thickness).

The existence of the interlayer has already been proven for other polymers such as polyethylene terephthalate (PET) and HDPE $[14,15,23,28]$, and in the case of HDPE its thickness has also been determined by X-ray spectroscopic analysis methods and DRIFT measurements [23]. For the raw polymer, about $50 \% \mathrm{sp}^{2}$ - and $50 \% \mathrm{sp}^{3}$-bound carbon were determined (Figure 9A). Considering the structure of the raw polymer, an almost pure $\mathrm{sp}^{3}$ structure is expected and the raw polymer is obviously dirty. This may be from residues resp. contaminants of the manufacturing process or softeners detaching from the polymer over time. The contamination was already detectable in the DRIFT measurements, where pronounced $\mathrm{sp}^{2}$ oscillations are visible (Figure 7). With the $\mathrm{O}_{2}$ plasma treatment, the amount of $\mathrm{sp}^{2}$ bonds present was strongly reduced and the surface was cleaned and activated. For this reason, all samples coated later on were first $\mathrm{O}_{2}$ plasma treated. With the application of a $10 \mathrm{~nm}$ thick a-C:H layer, the proportion of $\mathrm{sp}^{2}$ bonds increases again at the cost of decreasing $\mathrm{sp}^{3}$ bonds. This trend continues with increasing layer thickness until a thickness of $30 \mathrm{~nm}$ is reached. Here, the $\mathrm{sp}^{3}$ bonds have the lowest proportion and the layer composition remains almost constant up to $50 \mathrm{~nm}$. The increased sp ${ }^{3}$ content up to $30 \mathrm{~nm}$ is probably due to fragments of the base polymer, which are deposited in the interlayer phase with layer components. With increasing layer thickness, their percentage in the interlayer decreases, since the base material is no longer available due to possible erosion processes. The interlayer phase ends with a layer thickness of about $30 \mathrm{~nm}$ and pure a-C:H growth begins. After reaching $50 \mathrm{~nm}$ film thickness, the $\mathrm{sp}^{3}$ content increases again but reaches only $23 \%$ at $80 \mathrm{~nm}$. At $100 \mathrm{~nm}$, this value is again $17 \%$. From the completion of the interlayer to $100 \mathrm{~nm}$ layer thickness, the value of $\mathrm{sp}^{2}$ - and $\mathrm{sp}^{3}$-bound carbon is almost constant, even if there are small fluctuations. The dominance of $\mathrm{sp}^{2}$ bonds and decreasing proportion of $\mathrm{sp}^{3}$ bonds, which are visible in XPS, were already seen in the DRIFT measurements. The CA measurements also indicate a strong $\mathrm{sp}^{2}$ dominance for thin films, and the increase in $\mathrm{sp}^{3}$ bonds at $80 \mathrm{~nm}$ is also visible there. Therefore, all techniques reveal a very similar behavior.

Figure 9B shows the thicker layers from 100 to $2000 \mathrm{~nm}$. If the layer thickness increases, the bonding ratio at the surface of the a-C:H layer starts to change. The proportion of $\mathrm{sp}^{3}$ 
bonds increases strongly, and at $500 \mathrm{~nm}$ the bond ratio changes to $\mathrm{sp}^{3}$-dominated a-C:H growth. At $1000 \mathrm{~nm}$, about $83 \%$ of the carbon is $\mathrm{sp}^{3}$ bound at the surface. With the step to $1500 \mathrm{~nm}$, the proportion of $\mathrm{sp}^{2}$ bonds increases strongly again to $43 \%$. This is due to the dehydrogenation of the layer. Hydrogen leaves the layer at the expense of the $\mathrm{sp}^{3}$ bonds. This leads to a re-hybridization of the carbon atom orbitals. The now free bonds of the previously $\mathrm{sp}^{3}$-bound carbon changes into $\mathrm{sp}^{2}$-hybridized carbon clusters. The decrease in $\mathrm{sp}^{3}$ bonds in favor of increasing $\mathrm{sp}^{2}$ bonds was already visible in the DRIFT (Figure 8) starting at $1500 \mathrm{~nm}$. Moreover, the coalescence phenomenon of the fusion of grains on the surface takes place in this region, as demonstrated by some authors [14]. This behavior has already been demonstrated for HDPE $[14,23]$. If the thickness of the layer increases again, the effect decreases, and carbon is again strongly sp ${ }^{3}$ bound at $2000 \mathrm{~nm}$. The XPS results clearly show that layer growth up to $100 \mathrm{~nm}$ is sp ${ }^{2}$ dominated and towards thicker layers a more rigid, $\mathrm{sp}^{3}$-dominated carbon network is present on the surface. Exceptions are the interlayer region, which is limited to the first $30 \mathrm{~nm}$ layer thickness and the zone of dehydrogenation at $1500 \mathrm{~nm}$ a-C:H layer.

For thin layers, additional NEXAFS measurements have been performed. The spectra of the $\mathrm{O}_{2}$ plasma-treated PA6 together with various thin a-C:H layers on PA6 $(10,30$, and $50 \mathrm{~nm}$ ) are shown in Figure 10. The recording and evaluation of the raw data are performed as described earlier in the Section 2.4 experimental section (2.4). In consideration of the work of other groups, the peak positions were determined as follows: $\mathrm{C}=\mathrm{C} \pi(284.85 \mathrm{eV})$, $\mathrm{C}-\mathrm{H}(286.15 \mathrm{eV}), \mathrm{C}-\mathrm{C}(288.35 \mathrm{eV})$, and $\mathrm{C}=\mathrm{C} \sigma(292.55 \mathrm{eV})$ [52-56]. For a better overview, the figure is divided in three areas: $\mathrm{A}$ for the full spectra of the carbon $\mathrm{C} \mathrm{K}$-edge from $280-320 \mathrm{eV}$, B for the area of $293-287 \mathrm{eV}$ for the $\mathrm{C}=\mathrm{C} \pi$, and $\mathrm{C}$ from $287-293 \mathrm{eV}$ for the $\mathrm{C}-\mathrm{C}$ binding.
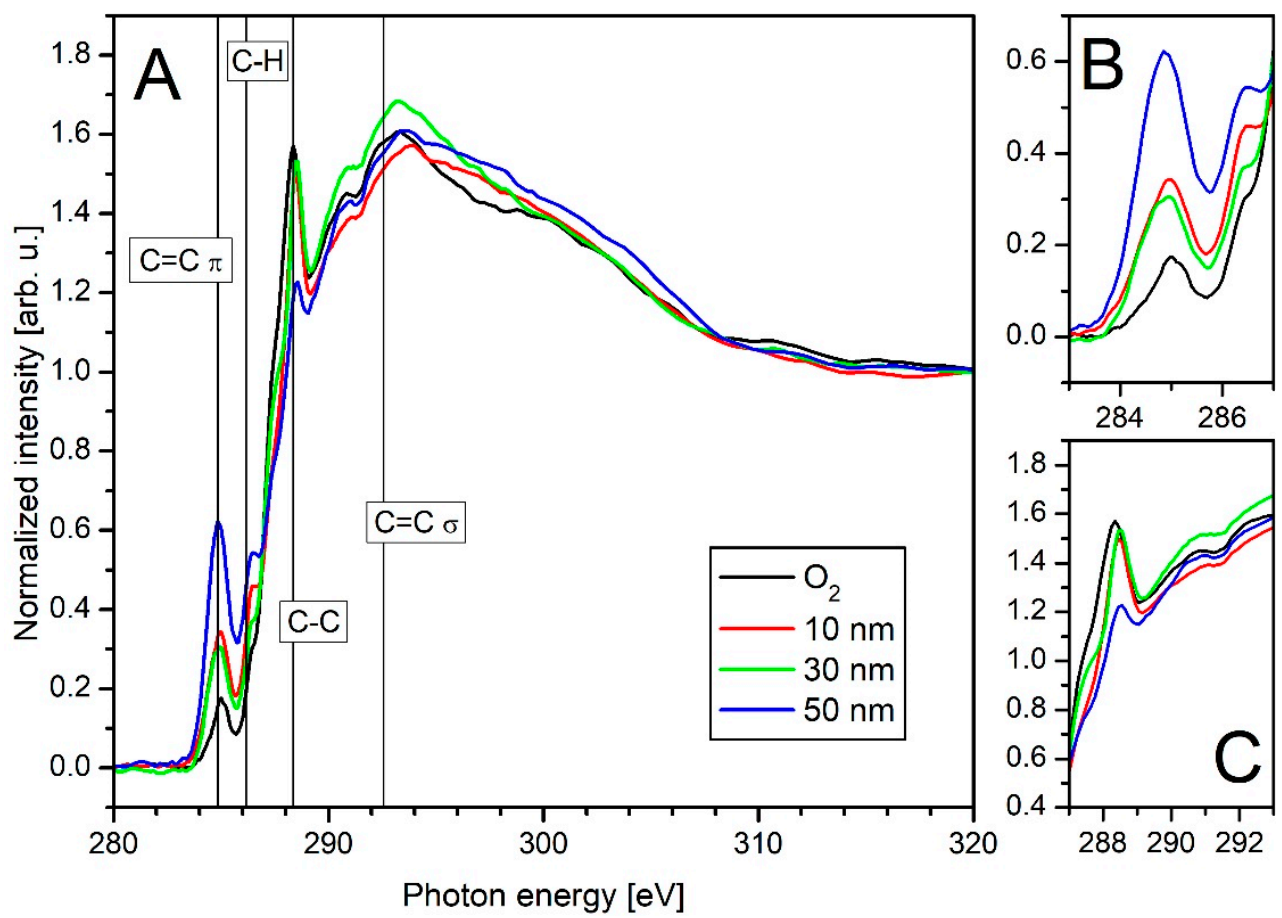

Figure 10. C K-edge NEXAFS measurements for PA6 coated with thin layers of a-C:H: (A) shows the full spectra; $(\mathbf{B}, \mathbf{C})$ present detailed photon energy intervals for carbon relevant peaks. (B): 283.00 to $287.00 \mathrm{eV}$ for the $\mathrm{C}=\mathrm{C} \pi$ peak $(284.85 \mathrm{eV})$ and the $\mathrm{C}-\mathrm{H}$ peak $(286.15 \mathrm{eV}) ;(\mathbf{C}): 287.00$ to $293.00 \mathrm{eV}$ for the $\mathrm{C}-\mathrm{C}$ and $\mathrm{C}=\mathrm{C} \sigma(288.15 \mathrm{eV}$ and $292.58 \mathrm{eV})$.

For the $\mathrm{O}_{2}$ plasma-treated sample (black curve) it is noticeable that the $\mathrm{C}=\mathrm{C} \pi$ peak belonging to the $\mathrm{sp}^{2}$ is only very weakly pronounced at $284.85 \mathrm{eV}$, while the $\mathrm{C}-\mathrm{C}$ peak, which represents the $\mathrm{sp}^{3}$ bonds, is strongly emphasized. This corresponds to the previous DRIFT and XPS results. With the application of a $10 \mathrm{~nm}$ a-C:H layer (red curve), the $\mathrm{sp}^{2}$ 
fraction increases, but the $\mathrm{sp}^{3}$ fraction remains almost unchanged. In addition to the $\mathrm{sp}^{3}$ bonds $\left(C-C\right.$ peak) of the substrate, there are also $\mathrm{sp}^{2}$ bonds $(C=C \pi$ peak) detectable due to the deposited layer. If the layer thickness is increased to $30 \mathrm{~nm}$ (green curve), a spectrum similar to that of the $10 \mathrm{~nm}$ sample is obtained. In both curves, the $\mathrm{sp}^{3}$ content most likely comes from the base material and is part of the interlayer. However, if the layer thickness of $50 \mathrm{~nm}$ is reached (blue curve), the measured spectrum changes significantly. The $\mathrm{C}=\mathrm{C} \pi$ increases strongly while the $\mathrm{C}-\mathrm{C}$ peak almost disappears. The reason for the disappearance of the $\mathrm{C}-\mathrm{C}$ peak is that it was caused by the base material which was mixed with the a-C:H layer in the interlayer. At $50 \mathrm{~nm}$ layer thickness, only the pure a-C:H layer is measured. The end of the interlayer phase is therefore specified between 30 and $50 \mathrm{~nm}$ thickness, which was already shown in the AFM, CA, DRIFT, and XPS measurements.

\section{Conclusions}

Polymer PA6 was coated with a-C:H layers in various thicknesses (10-2000 nm) using RF-PECVD generated acetylene plasma. The a-C:H layers were analyzed in two separate ranges: thin ones up to $100 \mathrm{~nm}$ to investigate the interlayer phase and thick layers between 100 and $2000 \mathrm{~nm}$ to investigate the dehydrogenation. The SEM images show stable a-C:H layers on PA6 samples, provided that the layer thickness of $1500 \mathrm{~nm}$ is not exceeded. Here, dehydrogenation also takes place, leading to a decrease in $\mathrm{sp}^{3}$ bonds in favor of $\mathrm{sp}^{2}$ bonds. The layer failure can be attributed to a stress reduction due to the $\mathrm{sp}^{3}$ dominance still present in this region.

AFM, CA, DRIFT, and XPS measurements show that the interlayer formation for a-C:H films on PA6 is completed by $40 \mathrm{~nm}$. In the AFM measurements, a homogeneous grain structure can be seen from here on. In the CAs, a relatively constant angle for the thin films is obtained after $40 \mathrm{~nm}$. In XPS, the $\mathrm{sp}^{3}$ content, which is lifted from the raw material into the interlayer mixed phase, is almost constant and low and a pure, $\mathrm{sp}^{2}$ containing a-C:H layer grows up. This behavior changes only after the layer thickness exceeds $100 \mathrm{~nm}$ and the carbon in the layer begins to be more strongly $\mathrm{sp}^{3}$ bound. The SEM and AFM measurements show equally stable growth. In the further course, the $\mathrm{sp}^{3}$ content increases significantly until dehydrogenation takes place at $1500 \mathrm{~nm}$ and stress-induced layer failure occurs later on.

Furthermore, it can be seen that the bonding ratios of the carbon atoms depend not only on the selected plasma parameters, but also on the achieved layer thickness, which clearly underlines the changing character of the a-C:H layer with increasing thickness. Both DRIFT and XPS measurements show a change between $\mathrm{sp}^{3}$ - and $\mathrm{sp}^{2}$-dominant bound layers. Since the change in bond dominance also causes a change in the properties of the applied layer, these can be controlled accordingly and adjusted by the layer thickness. The thickness and the chemical environment of the interlayer between PA6 and the a-C:H layer could also be determined, very accurately, to $40 \mathrm{~nm}$. This value is therefore very pronounced and also explains the high stability of the applied a-C:H layer before it breaks up at $1750 \mathrm{~nm}$. The dehydrogenation of the layer at high thicknesses, which is also known for other coated polymers, could also be proven.

In the process of the studies, it was shown that a-C:H layers can be deposited successfully on the PA6 material and remain stable (= without cracks) up to a thickness of $1500 \mathrm{~nm}$. The layer also adheres properly to the polymer (interlayer $=40 \mathrm{~nm}$ ). It is therefore possible to refine PA6 for applications such as in the (food) packaging sector (e.g., changed barrier effects).

Supplementary Materials: The following are available online at https: / www.mdpi.com/article/ 10.3390/polym13111886/s1, Figure S1: XPS C1s Peak deconvolution for the reference, $\mathrm{O}_{2}$ plasma treated sample and the thin layers from 10-100 nm a-C:H film thickness, Figure S2: XPS C1s Peak deconvolution for the PA6 samples coated with thick a-C:H layers (300-2000 nm).

Author Contributions: Conceptualization of the study, developing and organization of processes was arranged by T.S. and C.B.F.; T.S. prepared the samples and performed the data acquisition 
and evaluation of XPS and NEXAFS, evaluation of SEM results, overall data curation, visualization and wrote the manuscript draft. H.L. contributed in terms of contact angle, AFM and DRIFT measurements, their evaluation and visualization. L.B. and M.F. contributed in the acquisition of synchrotron measurements, XPS and NEXAFS. Y.B. arranged SEM imaging of thin layers $(<1000 \mathrm{~nm})$ and M.B. SEM imaging of thick layers (1000-2000 nm) and were supervised by B.H., T.S. and C.B.F.; T.S. and C.B.F. validated the results, reviewed and edited the manuscript. Both S.W. and C.B.F. contributed in terms of funding acquisition, project administration, supervision and overall guidance in the study. All authors have read and agreed to the published version of the manuscript.

Funding: T.S., L.B., and C.B.F. gratefully acknowledge the financial support (funding agreement BESSY 2: 145 and 225) provided by the Helmholtz-Zentrum Berlin (HZB), Germany.

Institutional Review Board Statement: Not applicable.

Informed Consent Statement: Not applicable.

Data Availability Statement: The data presented in this study are available on request from the corresponding author.

Acknowledgments: The authors thank Heinz Busch (NTTF Coatings GmbH, Rheinbreitbach, Germany) for the possibility of industrial coating of the samples. We also thank Joachim Scholz (University of Koblenz-Landau, Department of Chemistry) for the DRIFT equipment and Alexei Nefedov from KIT (Karlsruhe Institute for Technology, Group: Chemistry of oxidic and organic interfaces; X-ray and Electron Spectroscopy at Interfaces) for beamtime support. We thank HZB for the allocation of synchrotron radiation beamtime. The authors thankfully acknowledge the financial support by the Helmholtz-Zentrum Berlin (HZB), Germany.

Conflicts of Interest: The authors declare no conflict of interest.

\section{References}

1. Hellerich, W.; Harsch, G.; Haenle, S. Werkstoff-Führer Kunststoffe: Eigenschaften, Prüfungen, Kennwerte; mit 64 Tabellen, 7. überarb. und erw. Aufl.; Carl Hanser Verlag GmbH: München, Germany, 1996.

2. Döring, E. Polypropylene and Polyamide Developments in the European Automotive Industry; SAE Technical Paper Series; SAE International: Warrendale, PA, USA, 1983.

3. Nandhini, R.; Moorthy, M.K.; Muthukumaran, S.; Kumaran, S. Influence of process variables on the characteristics of friction-stirwelded polyamide 6,6 joints. Mater. Werkst. 2019, 50, 1139-1148. [CrossRef]

4. Félix, J.S.; Monteiro, M.; Manzoli, J.E.; Padula, M.; Pezo, D.; Romero, J.; Nerín, C. Identification and migration of degradation compounds from irradiation of multilayer polyamide 6 films for meat foodstuffs and cheese. Anal. Bioanal. Chem. 2008, 391, 847-857. [CrossRef]

5. Unal, H.; Mimaroglu, A. Friction and wear performance of polyamide 6 and graphite and wax polyamide 6 composites under dry sliding conditions. Wear 2012, 289, 132-137. [CrossRef]

6. Karsli, N.G.; Aytac, A. Tensile and thermomechanical properties of short carbon fiber reinforced polyamide 6 composites. Compos. Part B Eng. 2013, 51, 270-275. [CrossRef]

7. Deopura, B.L. Polyesters and Polyamides; Woodhead Publishing: Cambridge, UK; Textile Institute: Boca Raton, FL, USA, 2008.

8. Sabbatini, L. Polymer Surface Characterization; De Gruyter: Boston, MA, USA, 2014.

9. Andrady, A.L.; Neal, M.A. Applications and societal benefits of plastics. Philos. Trans. R. Soc. B Biol. Sci. 2009, 364, 1977-1984. [CrossRef] [PubMed]

10. Couderc, P.; Catherine, Y. Structure and physical properties of plasma-grown amorphous hydrogenated carbon films. Thin Solid Film 1987, 146, 93-107. [CrossRef]

11. Grill, A. Plasma-deposited diamondlike carbon and related materials. IBM J. Res. Dev. 1999, 43, 147-162. [CrossRef]

12. Rohrbeck, M.; Fischer, C.; Wehner, S.; Meier, J.; Manz, W. DLC-coated pure bioplastic foil. Vak. Forsch. Prax. 2014, 26, 42-47. [CrossRef]

13. Rohrbeck, M.; Körsten, S.; Fischer, C.B.; Wehner, S.; Kessler, B. Diamond-like carbon coating of a pure bioplastic foil. Thin Solid Film 2013, 545, 558-563. [CrossRef]

14. Catena, A.; Agnello, S.; Rösken, L.M.; Bergen, H.; Recktenwald, E.; Bernsmann, F.; Busch, H.; Cannas, M.; Gelardi, F.M.; Hahn, B.; et al. Characteristics of industrially manufactured amorphous hydrogenated carbon (a-C: H) depositions on high-density polyethylene. Carbon 2016, 96, 661-671. [CrossRef]

15. Catena, A.; Guo, Q.; Kunze, M.R.; Agnello, S.; Gelardi, F.M.; Wehner, S.; Fischer, C.B. Morphological and Chemical Evolution of Gradually Deposited Diamond-Like Carbon Films on Polyethylene Terephthalate: From Subplantation Processes to Structural Reorganization by Intrinsic Stress Release Phenomena. ACS Appl. Mater. Interfaces 2016, 8, 10636-10646. [CrossRef] [PubMed] 
16. Catena, A.; Kunze, M.R.; Agnello, S.; Gelardi, F.M.; Wehner, S.; Fischer, C.B. Amorphous hydrogenated carbon (a-C: H) depositions on polyoxymethylene: Substrate influence on the characteristics of the developing coatings. Surf. Coat. Technol. 2016, 307, 658-665. [CrossRef]

17. Fruth, W.; Meerkamm, H.; Krumpiegl, T.; Schaufler, C.; Erkens, G.; Ruttor, M. Tribological behaviour of PVD-coated PA plastic material sliding against metal counterparts. Surf. Coat. Technol. 1999, 120-121, 470-475. [CrossRef]

18. Paul, R.; Das, S.N.; Dalui, S.; Gayen, R.N.; Roy, R.K.; Bhar, R.; Pal, A.K.; Das, S. Synthesis of DLC films with different sp ${ }^{2} / \mathrm{sp}^{3}$ ratios and their hydrophobic behaviour. J. Phys. D Appl. Phys. 2008, 41,1-7. [CrossRef]

19. Mohagheghpour, E.; Rajabi, M.; Gholamipour, R.; Larijani, M.M.; Sheibani, S. Ion beam energy dependence of surface and structural properties of amorphous carbon films deposited by IBSD method on Ni-Cu alloy. J. Mater. Res. 2017, 32, 1258-1266. [CrossRef]

20. Robertson, J. Plasma Deposition of Diamond-Like Carbon. Jpn. J. Appl. Phys. 2011, 50, 1-8. [CrossRef]

21. Robertson, J. Diamond-like amorphous carbon. Mater. Sci. Eng. R Rep. 2002, 37, 129-281. [CrossRef]

22. Lee, S.C.; Tai, F.C.; Wei, C.H. Correlation between $\mathrm{sp}^{2} / \mathrm{sp}^{3}$ ratio or hydrogen content and water contact angle in hydrogenated DLC film. Mater. Trans. 2007, 48, 2534-2538. [CrossRef]

23. Schlebrowski, T.; Rouabeh, W.; Wehner, S.; Fischer, C.B. Specifying the interlayer turning point and dehydrogenation in aC:H layers plasma deposited on high-density polyethylene with X-ray synchrotron techniques. Thin Solid Film 2019, 691, 1-6. [CrossRef]

24. Schlebrowski, T.; Beucher, L.; Bazzi, H.; Hahn, B.; Wehner, S.; Fischer, C.B. Prediction of a-C: H layer failure on industrial relevant biopolymer polylactide acide (PLA) foils based on the $\mathrm{sp}^{2} / \mathrm{sp}^{3}$ ratio. Surf. Coat. Technol. 2019, 368, 79-87. [CrossRef]

25. Schlebrowski, T.; Beucher, L.; Bazzi, H.; Hahn, B.; Wehner, S.; Fischer, C.B. Changing Contents of Carbon Hybridizations in Amorphous Hydrogenated Carbon Layers (a-C: H) on Sustainable Polyhydroxybutyrate (PHB) Exhibit a Significant Deterioration in Stability, Depending on Thickness. C 2019, 5, 52. [CrossRef]

26. Schlebrowski, T.; Acharchi, H.; Hahn, B.; Wehner, S.; Fischer, C.B. 202 Refinement of Sustainable Polybutylene Adipate Terephthalate (PBAT) with Amorphous Hydrogenated Carbon Films (a-C:H) Revealing Film Instabilities Influenced by a ThicknessDependent Change of $\mathrm{sp}^{2} / \mathrm{sp}^{3}$ Ratio. Materials 2020, 13, 1077. [CrossRef]

27. Koidl, P.; Wild, C.; Dischler, B.; Wagner, J.; Ramsteiner, M. Plasma Deposition, Properties and Structure of Amorphous Hydrogenated Carbon Films. Mater. Sci. Forum 1990, 52, 41-70. [CrossRef]

28. Fischer, C.B.; Rohrbeck, M.; Wehner, S.; Richter, M.; Schmeißer, D. Interlayer formation of diamond-like carbon coatings on industrial polyethylene: Thickness dependent surface characterization by SEM, AFM and NEXAFS. Appl. Surf. Sci. 2013, 271, 381-389. [CrossRef]

29. Catena, A.; McJunkin, T.; Agnello, S.; Gelardi, F.M.; Wehner, S.; Fischer, C.B. Surface morphology and grain analysis of successively industrially grown amorphous hydrogenated carbon films (a-C:H) on silicon. Appl. Surf. Sci. 2015, 347, 657-667. [CrossRef]

30. Armaroli, T.; Bécue, T.; Gautier, S. Diffuse Reflection Infrared Spectroscopy (Drifts). Oil Gas Sci. Technol. 2004, 59, 215-237. [CrossRef]

31. D'Souza, L.; Devi, P.; Kamat, T.; Naik, C.G. Diffuse reflectance infrared fourier transform spectroscopic (DRIFTS) investigation of E.coli, Staphylococcus aureus and Candida albicans. Indian J. Mar. Sci. 2009, 38, 45-51.

32. Günzler, H.; Gremlich, H.U. IR Spectroscopy: An. Introduction; Wiley-VCH: Weinheim, Germany, 2002.

33. Fang, D.; He, F.; Xie, J.; Xue, L. Calibration of Binding Energy Positions with C1s for XPS Results. J. Wuhan Univ. Technol. Mat. Sci. Ed. 2020, 35, 711-718. [CrossRef]

34. Nefedov, A.; Wöll, C. Advanced Applications of NEXAFS Spectroscopy for Functionalized Surfaces. In Book Surface Science Techniques; Bracco, G., Holst, B., Eds.; Springer: Berlin/Heidelberg, Germany, 2013.

35. Watts, B.; Thomsen, L.; Dastoor, P.C. Methods in carbon K-edge NEXAFS: Experiment and Analysis. J. Chem. Phys. 2014, 140, 105-120. [CrossRef]

36. Banerjee, D.; Mukherjee, S.; Chattopadhyay, K. Controlling the surface topology and hence the hydrophobicity of amorphous carbon thin films. Carbon 2010, 48, 1025-1031. [CrossRef]

37. Barthlott, W.; Neinhuis, C. Purity of the sacred lotus, or escape from contamination in biological surfaces. Planta 1997, 202, 1-8. [CrossRef]

38. Feng, L.; Li, S.; Li, Y.; Li, H.; Zhang, L.; Zhai, J.; Song, Y.; Liu, B.; Jiang, L.; Zhu, D. Super-Hydrophobic Surfaces. Adv. Mater. 2002, 14, 1857-1860. [CrossRef]

39. Werder, T.; Walther, J.H.; Jaffe, R.L.; Halicioglu, T.; Koumoutsakos, P. On the Water-Carbon Interaction for Use in Molecular Dynamics Simulations of Graphite and Carbon Nanotubes. J. Phys. Chem. B 2003, 107, 1345-1352. [CrossRef]

40. Zhou, Y.; Wang, B.; Song, X.; Li, E.; Li, G.; Zhao, S.; Yan, H. Control over the wettability of amorphous carbon films in a large range from hydrophilicity to super-hydrophobicity. Appl. Surf. Sci. 2006, 253, 2690-2694. [CrossRef]

41. Bismarck, A.; Brostow, W.; Chiu, R.; Lobland, H.E.H.; Ho, K.K. Effects of surface plasma treatment on tribology of thermoplastic polymers. Polym. Eng. Sci. 2008, 48, 1971-1976. [CrossRef]

42. Ostrovskaya, L.; Perevertailo, V.; Ralchenko, V.; Dementjev, A.; Loginova, O. Wettability and surface energy of oxidized and hydrogen plasma-treated diamond films. Diam. Relat. Mater. 2002, 11, 845-850. [CrossRef]

43. Ostrovskaya, L. Studies of diamond and diamond-like film surfaces using XAES, AFM and wetting. Vacuum 2002, 68, 219-238. [CrossRef] 
44. Piazza, F.; Morell, G. Wettability of hydrogenated tetrahedral amorphous carbon. Diam. Relat. Mater. 2009, 18, 43-50. [CrossRef]

45. Tay, B.K.; Sheeja, D.; Lau, S.P.; Guo, J. Study of surface energy of tetrahedral amorphous carbon films modified in various gas plasma. Diam. Relat. Mater. 2003, 12, 2072-2076. [CrossRef]

46. Extrand, C.W. Water contact angles and hysteresis of polyamide surfaces. J. Colloid Interface Sci. 2002, 248, 136-142. [CrossRef]

47. Tomasella, E.; Thomas, L.; Dubois, M.; Meunier, C. Structural and mechanical properties of a-C. Diam. Relat. Mater. 2004, 13, 1618-1624. [CrossRef]

48. Veres, M.; Koos, M.; Pócsik, I. IR study of the formation process of polymeric hydrogenated amorphous carbon film. Diam. Relat. Mater. 2002, 11, 1110-1114. [CrossRef]

49. Dietrich, P.M.; Horlacher, T.; Girard-Lauriault, P.L.; Gross, T.; Lippitz, A.; Min, H.; Wirth, T.; Castelli, R.; Seeberger, P.H.; Unger, W.E.S. Adlayers of Dimannoside Thiols on Gold: Surface Chemical Analysis. Langmuir 2011, 27, 4808-4815. [CrossRef] [PubMed]

50. Solomon, J.; Madix, R.; Stöhr, J. Orientation and absolute coverage of benzene, aniline, and phenol on Ag (110) determined by NEXAFS and XPS. Surf. Sci. 1991, 255, 12-30. [CrossRef]

51. Tai, F.C.; Lee, S.C.; Wei, C.H.; Tyan, S.L. Correlation between $\mathrm{I}_{\mathrm{D}} / \mathrm{I}_{\mathrm{G}}$ Ratio from Visible Raman Spectra and $\mathrm{sp}^{2} / \mathrm{sp}^{3}$ Ratio from XPS Spectra of Annealed Hydrogenated DLC Film. Mater. Trans. 2006, 47, 1847-1852. [CrossRef]

52. Dhez, O.; Ade, H.; Urquhart, S.; Urquhart, S. Calibrated NEXAFS spectra of some common polymers. J. Electron. Spectrosc. Relat. Phenom. 2003, 128, 85-96. [CrossRef]

53. Diaz, J.; Monteiro, O.R.; Hussain, Z. Structure of amorphous carbon from near-edge and extended x-ray absorption spectroscopy. Phys. Rev. B 2007, 76, 094201. [CrossRef]

54. Díaz, J.; Anders, S.; Zhou, X.; Moler, E.J.; Kellar, S.A.; Hussain, Z. Analysis of the $\pi^{*}$ and $\sigma^{*}$ bands of the x-ray absorption spectrum of amorphous carbon. Phys. Rev. B 2001, 64, 125204. [CrossRef]

55. Stöhr, J. NEXAFS Spectroscopy; Springer: Berlin/Heidelberg, Germany, 1992.

56. Brüster, B.; Amozoqueño, C.; Grysan, P.; Peral, I.; Watts, B.; Raquez, J.-M.; Dubois, P.; Addiego, F. Resolving Inclusion Structure and Deformation Mechanisms in Polylactide Plasticized by Reactive Extrusion. Macromol. Mater. Eng. 2017, 302, 1700326. [CrossRef] 